\title{
Repertorios lingüísticos y representación de la diversidad lingüística en Leticia(Colombia) y su periferia ${ }^{1}$
}

\author{
Santiago Sánchez Moreano ${ }^{2}$ \\ LABEX Empirical Foundations of Linguistics \\ ORCID ID : 0000-0002-8434-3726
}

Recibido : 25 de enero de 2019

Aceptado : 27 de febrero de 2019

\section{Resumen}

En este artículo se describe la representación de los repertorios lingüísticos (Gumperz, 1964) que tienen los estudiantes en escuelas de Leticia, ciudad colombiana situada en el trapecio amazónico y marcada por la diversidad sociolingüística y sociocultural de la región. Para esto, adopto, como método, la perspectiva empírica, biográfica y posestructuralista de B. Busch $(2012,2017,2018)$ quien sugiere que el estudio de los repertorios lingüísticos de los hablantes debe incluir la dimensión de la experiencia vivida a través, por

\section{Abstract}

This paper describes the representation of the linguistic repertoires (Gumperz 1964) of students in schools in Leticia, a Colombian sociocultural and sociolinguistically diverse city in the Amazonas border. To do this, I followed, as a methodological tool, the empirical, biographical and poststructuralist perspective of the linguistic repertoire (Busch 2012, 2017, 2018) which suggests that the analysis of the speakers' linguistic repertoires should include the dimension of the lifeworld experience through, for example, linguistic portraits.

1 Linguistic repertoires and language diversity representations in Leticia (Colombia) and its periphery

2 Magister en Littérature, Philologie, Linguistique, por la Université Sorbonne (Paris 4) y Doctor en Sciences du Langage, por la Université Sorbonne Paris Cité (Paris 7). Actualmente es Lecteur en el Département d'Etudes Ibériques et Latino-Américaines, Université Sorbonne Nouvelle (Paris 3) y cursa su Postdoctorado en LABEX Empirical Foundations of Linguistics, LC1 Multifactorial Analysis of Language Change, UMR 8202 Structure et Dynamique des Langues (Paris). Correo : sanchez. moreano@gmail.com 
ejemplo, de retratos lingüísticos. Estos son utilizados aquí como instrumento de investigación para comprender cómo los hablantes experimentan, interpretan y representan sus propios repertorios y prácticas de lenguaje heterogéneas. Así, a través del análisis interpretativo de retratos plurilingües en escuelas de Leticia observaremos cómo los estudiantes expresan, perciben y construyen la diversidad del contexto social en el que están inmersos a pesar de los discursos e ideologías dominantes $y$ homogeneizadoras.

Palabras clave: repertorios lingüísticos, diversidad lingüística, experiencia vivida, Leticia (Amazonas)
These linguistic portraits are used here as a research tool to understand how speakers experience, interpret, and represent their heterogeneous linguistic repertoires and language practices. Thus, through the analysis of multilingual portraits by students in Leticia, we will observe how students express, perceive and build up the sociocultural and linguistic diversity in which they are immersed, challenging the existence of dominant and homogenizing discourses and ideologies.

Keywords: linguistic repertoires, linguistic diversity, lifeworld experience, Leticia (Amazonas)

\section{Introducción}

Leticia es una ciudad colombiana, capital del departamento del Amazonas, que se sitúa en el trapecio amazónico en la frontera entre Colombia, Perú y Brasil. Su diversidad sociocultural y lingüística y la de su periferia, ampliamente documentada en la literatura (Chaumeil, 2000; de Campos Barbosa, 2008; Fagua Rincón, 2004; Molina, 2008; Gasché \& Vela Mendoza, 2011), se ilustra con la presencia de grupos indígenas transfronterizos de la mayoría de etnias que habitan el trapecio amazónico (cocama, tikuna, yagua, witoto, etc.) y de poblaciones mestizas de los tres países. La movilidad transnacional, según Chaumeil (2000: 59), siempre ha sido activa y ha variado según las épocas. Por ejemplo, desde los años dos mil en adelante muchos peruanos han experimentado la movilidad hacia Brasil y Colombia por cuestiones económicas, entre otras, y esa tendencia se mantiene hasta nuestros días. Según Echeverri Restrepo (2011: 15-17), en la Amazonia se ha venido dando el surgimiento de un nuevo tipo de sociedad que no es solamente indígena, sino que cuenta también con grandes componentes de inmigrantes y de poblaciones mestizas. En este senti- 
do, la sociedad rural amazónica es fundamentalmente diversa o, como lo dicen Gasché y Vela Mendoza (2011), es una sociedad bosquesina ${ }^{3}$.

A pesar de esto, la diversidad de Leticia y de su periferia, y de manera más amplia de la región amazónica, está a menudo en conflicto con el peso hegemónico de la lengua mayoritaria, el español. Sin embargo, las implicaciones de este "conflicto" van más allá de lo lingüístico y pueden trascender a lo social y a lo cultural. Pueden ser del orden de la negociación de identidades y posicionamientos sociales (Du Bois, 2007), de la manifestación de posturas de afiliación, asimilación o resistencia, de la heterogeneización de las prácticas de lenguaje de los actores sociales y de la emergencia de formas lingüísticas y culturales innovadoras. Todos estos fenómenos son representativos de sociedades superdiversas (Vertovec, 2007, Blommaert y Rampton, 2011) en las que las comunidades de habla, pensadas antes como entidades estables y bien delimitadas, están sujetas a cambios rápidos. En efecto, en sociedades superdiversas los hablantes participan en diferentes y variadas comunidades de práctica, muchas veces de-territorializadas (Busch, 2012: 505). Además, y de manera no menos importante, como sucede en otros contextos de movilidad en el mundo (ver, por ejemplo, Sánchez, 2007), muchos de estos grupos mantienen relaciones transnacionales permanentes con sus lugares y comunidades de origen a través de incesantes vaivenes, del intercambio de flujos importantes de información, de intercambios económicos, materiales, inmateriales, etc.

Una manera de comprender estas implicaciones es estudiando los repertorios lingüísticos de los actores sociales desde la perspectiva de Busch $(2012,2017,2018)$. Así, en este trabajo, considero que los repertorios lingüísticos se constituyen a través de la experiencia lingüística vivida (spracherleben) y que su estudio empírico e interpretativo permite comprender el mundo experimentado/vivido (lifeworld) de los actores sociales. Analizo datos empíricos y biográficos sobre los repertorios lingüísticos a través de retratos plurilin-

3 "El bosquesino [...] es una persona que vive en una comunidad rural (o que ha migrado a una ciudad adaptándose a la vida urbana en los barrios periféricos), en cuyo marco material, ambiental, social y cultural está desarrollando sus actividades cotidianas. Para comprender la lógica de vida subjetiva -las motivaciones, acciones, finalidades y priorizaciones- de esta persona tenemos, por lo tanto, que conocer este marco multifacético y las actividades, las conductas y los discursos en los que se concretiza y se vuelve observable y comprensible la vida bosquesina, -a condición que no proyectemos a priori prejuicios y nuestros propios valores urbanos sobre el universo socio-cultural bosquesino y estemos dispuestos a descubrir su alteridad: una forma de vida, un lenguaje y valores distintos de los nuestros." (Gasché y Vela Mendoza, 2011: 35). 
gües recolectados y comentados en escuelas de Leticia y de su periferia. El objetivo es describir las representaciones de la diversidad sociolingüística que tienen los jóvenes indígenas y no indígenas en estos espacios de formación. Las escuelas, como espacios institucionales, están determinadas por las relaciones de poder discursivamente manifestadas (Purkarthofer, 2018). Al mismo tiempo, están constreñidas por las ideologías lingüísticas homogeneizantes, a pesar de los esfuerzos de muchos educadores y actores sociales locales por reconocer y reivindicar la pluralidad.

Este artículo está constituido de una primera sección en la que se aborda la diversidad sociocultural de Leticia en el ámbito amazónico. La segunda sección incluye los fundamentos teóricos y metodológicos para el estudio de los repertorios lingüísticos desde la perspectiva de la experiencia vivida. La tercera sección describe el contexto sociolingüístico institucional y la forma como fueron levantados los datos empíricos para su análisis. La cuarta sección se dedica al análisis de los retratos plurilingües y de los comentarios y explicaciones por parte de los estudiantes desde una perspectiva interpretativa. Y en la última sección de este artículo se propone una discusión, así como algunos elementos de conclusión y de proyección.

\section{Diversidad sociocultural de Leticia, ciudad amazónica}

Leticia, ciudad de unos 39 mil habitantes según proyecciones del Departamento administrativo de estadísticas y censos de Colombia (DANE) para 2010, se sitúa en el llamado trapecio amazónico (frontera entre Colombia, Perú y Brasil). Su diversidad social, lingüística y cultural, así como la de su periferia, ha sido ampliamente documentada (Chaumeil, 2000; de Campos Barbosa, 2008; Fagua Rincón, 2004; Molina, 2008). Según el censo de 2005, el 25,9 \% de la población residente en Leticia se autoreconoce como indígena. En efecto, en Leticia y su periferia viven grupos indígenas transfronterizos de la mayoría de etnias del trapecio amazónico como los cocama, tikuna, yagua, witoto, etc. Asimismo, según este organismo, el 22,7 \% de la población nació en otro municipio o en otro país, en particular Brasil y Perú. La diversidad de Leticia refleja la de la región amazónica que, según Mahecha Rubio (2011: 295-296), es una de las más diversas de Colombia con más de 52 lenguas. Sin embargo, según Chaumeil (2000: 54), contrariamente a lo que se cree, las poblaciones de la Amazonia no se caracterizan por su sedentarización o asimilación a uno de los tres países fronterizos, sino por una fuerte movilidad transnacional marcada por el incesante vaivén entre los límites que separan los tres países. Por ejemplo, los tikuna suelen frecuentar los tres países 
cuando visitan a sus familiares, los yagua del Perú suelen negociar a mejores precios los productos que venden en los mercados colombianos, y los yagua brasileros son atraídos del lado colombiano por salarios más ventajosos (2000: 59).

En efecto, uno de los factores que hacen que la Amazonia sea un lugar de diversidad es la movilidad de sus poblaciones. Chaumeil (2000: 59) afirma que la movilidad transfronteriza siempre ha sido muy activa y ha variado según las épocas desde 1935, fecha del establecimiento de la triple frontera. En ese entonces el flujo migratorio fronterizo venía del Brasil hacia Colombia y Perú, lo que hace que más de la mitad de la población de Leticia sea de origen brasilero, según este autor. Algo similar sucedía con las familias brasileras instaladas en Caballococha en Perú o las primeras familias tikuna brasileras que poblaron en los años cincuenta esta localidad. En los años 2000 la tendencia parece invertirse. Muchos peruanos se desplazaban hacia Colombia y Brasil, tendencia que se mantiene hoy en día (2000: 59). De hecho, actualmente se observan muchos peruanos en los mercados de Tabatinga donde al parecer gozan de más libertad aduanera para comerciar sus productos.

Según Echeverri Restrepo (2011: 15), la Amazonia es por tanto una región que, a pesar del aparente aislamiento, ha estado interconectada con las otras regiones de Suramérica y del mundo lo que la hace heterogénea y abierta a las interacciones globales. En ella ha surgido "un nuevo tipo de sociedad, que no es solamente indígena, sino también con grandes componentes de inmigrantes y de poblaciones mestizas" (2011: 17). La sociedad rural amazónica es, como la describe Echeverri Restrepo, siguiendo el concepto de sociedades bosquesinas de Gasché y Vela Mendoza (2011), al mismo tiempo indígena, mestiza, pluriactiva, igualitaria, anárquica, festiva y multilingüe.

Sin embargo, la diversidad de Leticia y de su periferia, y más ampliamente de la región amazónica, está a menudo eclipsada por la presencia homogeneizadora del español, la lengua mayoritaria. En efecto, la población de Leticia es mayoritariamente hispanohablante y las poblaciones inmigrantes, en tanto que minorías, se encuentran a menudo en situación de minoración y de contacto asimétrico con respecto a la población mayoritaria. Esto genera relaciones desiguales entre individuos y grupos, lo que tiene implicaciones sociales y lingüísticas ya puestas en evidencia, pero aún poco descritas. Mahecha Rubio, por ejemplo, sugiere que las relaciones entre la población no indígena con la población indígena pueden tener efectos serios 
en la reproducción, utilización y supervivencia de las lenguas y los dialectos indígenas (2011: 295).

Según esta autora, los hablantes de estas lenguas minoritarias y minorizadas están a menudo en contacto con hablantes de variedades dialectales del español y del portugués. Esto supone, para ella, una amenaza para su supervivencia en términos de aprendizaje y transmisión, al mismo tiempo que supone un enriquecimiento para las variedades de lenguas mayoritarias habladas en la región. Asimismo, otro de los factores que afectan el aprendizaje y la transmisión de las lenguas ancestrales en los senos familiares y que favorecen el uso del español es la migración [movilidad] ${ }^{4}$ contemporánea a las cabeceras municipales y corregimientos (Mahecha Rubio, 2011: 297-298).

Por supuesto, la movilidad y los contactos de poblaciones tienen necesariamente implicaciones sociales, culturales y lingüísticas. Estos efectos son probablemente más visibles en contextos de ciudad y sus periferias. Algunas de las implicaciones pueden ser, por ejemplo, del orden de la negociación de identidades, de posicionamientos y posturas sociales, de la heterogeneización de las prácticas de lenguaje de los actores sociales, de la emergencia de formas lingüísticas innovadoras (Sánchez Moreano, 2018). Así, la diversidad lingüística y las implicaciones de la movilidad y del contacto de poblaciones en Leticia y su periferia se manifiestan y se perciben de múltiples maneras. Una de las formas de redescubrirla y de ponerla en evidencia es estudiando los repertorios lingüísticos desde la perspectiva de la experiencia vivida de los hablantes, como lo propone Busch (2012, 2017, 2018).

\section{El repertorio lingüístico como experiencia vivida}

En este trabajo se considera que los repertorios lingüísticos se constituyen a través de la experiencia lingüística vivida (spracherleben). Esta perspectiva considera que los hablantes, en situaciones de diversidad lingüística, crecen expuestos a varias lenguas, variedades de lengua o incluso a variedades estilísticas, pero también a las creencias, valores e ideologías lingüísticas (Kroskrity, 2006) que están ligadas a ellas. Así, los análisis que podemos hacer de sus repertorios o de la representación que los hablantes tienen de ellos se focalizan

4 En este trabajo, prefiero utilizar la palabra "movilidad" que permite cuestionar la visión estática que evoca el término "migración". 
menos en sus competencias lingüísticas y más en sus capacidades percibidas, es decir, en "el saber actuar en la vida diaria utilizando sus propios recursos plurilingües" (Purkarthofer, 2018: 202). Comprender cómo las personas se identifican lingüísticamente a sí mismas en contextos bilingües y multilingües, a través de procesos de auto-identificación contextualizada, permite poner de relieve, por ejemplo, la diversidad lingüística inherente de grupos de personas en situación de inmigración percibidos tradicionalmente como homogéneos (Fernández-Mallat, 2018: 163). Asimismo, hablar de repertorios y de recursos plurilingües implica a su vez un distanciamiento de la perspectiva de las lenguas como entidades establecidas y, como lo sugiere Busch (2012: 507), postula la necesidad de enriquecer el concepto de "repertorio" considerando las dimensiones históricas, ideológicas y biográficas de los hablantes.

El repertorio lingüístico es una noción que surge de la sociolingüística interaccional de J. Gumperz (1964). El concepto, que está estrechamente ligado al de comunidad de habla (Patrick, 2008) y comunidad de práctica (Meyerhoff, 2008), se define como un conjunto que "contiene todas las formas aceptadas de formular mensajes" y que "provee (al hablante) las herramientas para la comunicación diaria". Los hablantes escogen así las herramientas que necesitan en "función de los significados que quieren transmitir" (1964: 38). Interesado en fenómenos de alternancia de lenguas y codeswitching en contextos multilingües, Gumperz sugiere que en un repertorio plurilingüe las lenguas y dialectos forman un "todo", más allá de distinciones gramaticales. En este sentido, las lenguas y dialectos deben ser considerados como variedades constituyentes del mismo repertorio verbal (Gumperz 1964: 140). Sin embargo, la noción de Gumperz de repertorio verbal se focaliza sincrónicamente en los espacios de interacción social y no considera otros aspectos como las dimensiones históricas, ideológicas y biográficas de los hablantes. A este respecto, Busch (2012) afirma que los sujetos son moldeados y constituidos en su pensamiento, forma de hablar, sentimientos y deseos, por el poder de categorías sociales discursivamente establecidas. Para argumentar esto, Busch retoma los conceptos filosóficos de de-construcción de Jacques Derrida (1998) y de normatividad de Judith Butler (1997). El concepto de de-construcción de Derrida, que el filósofo elabora desde su propia biografía lingüística, apunta al hecho de que el repertorio lingüístico no solo debe incluir lo que uno tiene, sino lo que no tiene o lo que se le ha negado (a menudo por cuestiones socio-históricas), pero que está presente en términos de deseo. Por su parte, el concepto de normatividad de Butler se define como lo que se puede o debe decir y lo que no se puede o no debe decir. Esto ejerce una censura productiva que no solo es restrictiva 
y privativa, sino también formadora de los sujetos y legitimadora de las fronteras entre lenguas (Butler, 1997: 132, citada por Busch, 2012: 509). Aplicada a la cuestión de la relación entre repertorios lingüísticos y las lenguas como unidades discretas, esto significa que el poder restrictivo de las categorizaciones se siente particularmente cuando el lenguaje no está disponible, es decir, cuando la gente no es reconocida o no se reconocen como hablantes legítimos de una lengua en particular (Busch 2012: 509).

Según Busch, estos dos conceptos pueden contribuir a la elaboración de una noción de repertorio más expandida que pone en primer plano al sujeto y que abarca su dimensión corporal de percibir las cosas, de experimentar, de sentir y de desear (Busch 2012: 510). Esta es una noción expandida del repertorio lingüístico de corte posestructuralista que se sustenta en otras nociones y conceptos provenientes de las ciencias sociales, de la sociolingüística crítica y de la antropología lingüística. Uno de estos conceptos es el de superdiversidad (Blommaert \& Rampton, 2011; Vertovec, 2007) que intenta describir la interacción dinámica, en las sociedades modernas, de aspectos como la diversidad de poblaciones, las migraciones, la movilidad espacial y social, los orígenes étnicos, las relaciones transnacionales, las diferencias culturales, el estatus socio-económico de los individuos, etc.

Busch utiliza esta perspectiva posestructuralista y multimodal para describir empíricamente, a través de representaciones verbales, la experiencia lingüística y discursiva que viven los hablantes (profesores de escuela) en la frontera franco-alemana en las regiones de Saarland y Lorraine ${ }^{5}$. La idea era describir la representación que ellos tenían de las categorías de poder y de las ideologías lingüísticas a través de retratos lingüísticos. Para esto, se les pidió a los participantes que pensaran en el papel que juegan o han jugado sus códigos, lenguas, dialectos, variedades de lengua, medios de expresión y de comunicación, en sus vidas. Seguidamente, se les

\footnotetext{
5 De Jager, Tewson, Bedlow y Bodley (2016, citados por Busch, 2018: 3) afirman que los estudios que han seguido estas perspectivas desde los años 80 han tocado temas como la salud, los traumas, la desigualdad social, la promoción política, la migración, el desarrollo en comunidades y la educación, sobre todo en Canadá, Sudáfrica, Australia y en algunos países europeos. Asimismo, Purkarthofer (2017: 2), afirma que este enfoque ha sido desarrollado para trabajar las biografías multilingües y el uso de determinadas lenguas en el ámbito de la educación, la vida familiar y los medios (Busch 2006). También ha sido utilizada en estudios sobre el lenguaje y el trauma (Busch 2016).
} 


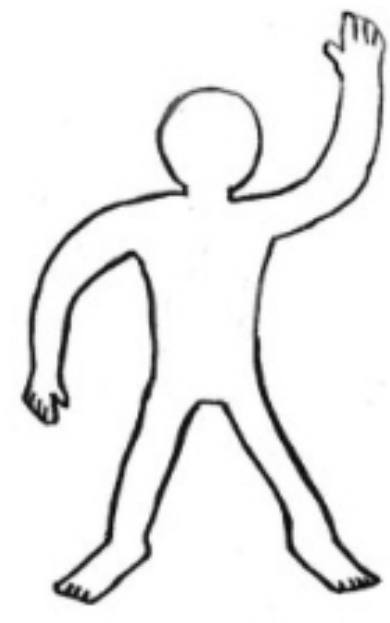

Figura 1. Patrón para la realización del retrato lingüístico (Busch, 2012: 511)

solicitó que los representaran en una silueta vacía (Figura 1) y con diferentes colores sin pensar en estas como categorías delimitadas o nacionales.

El uso de diferentes colores en la silueta permite identificar qué lenguas o variedades de lengua hacen parte de los repertorios lingüísticos de los hablantes y qué ideas y sentimientos están asociados a ellas. Así, los retratos lingüísticos se entienden como instrumentos que permiten dar un primer paso hacia un entendimiento de las prácticas lingüísticas cotidianas, de la experiencia corporal y emocional del lenguaje, pero también de las ideologías, actitudes y posturas hacia las lenguas y formas de hablar determinadas (Busch, 2018: 4).

En este sentido, Busch afirma que el cuerpo, representado por la silueta, se convierte en el marco referencial en el que se pueden estructurar varios tipos de marcos para la interpretación de metáforas. Entre las más comunes se encuentra la metáfora de la cabeza como el lugar del raciocinio, la del vientre o el abdomen como el lugar de las emociones, la del corazón como el lugar de la intimidad y de los sentimientos, la de las manos como el de la actividad social y el contacto con los demás (Busch, 2018: 10). Otra forma de estructurar la interpretación metafórica puede ser en función de la representación espacial. Así, lo interno vs lo externo pueden ser interpretados como metáforas de lo familiar y lo desconocido; el arriba y el abajo como metáfora de lo actual y lo lejano, pero también como metáfora de jerarquías; los espacios grandes y pequeños como metáfora de lo importante y lo menos importante. Asimismo, según Busch, también se pueden observar, en las representaciones, iconos, símbolos y otros ornamentos como flechas, luces, estrellas, corazones, banderas, etc. que pueden conducir también a interpretaciones metafóricas.

Los colores o matices diferentes utilizados en las siluetas suelen también ser asociados con connotaciones comunes. Así, el rojo se asocia a menudo con las emociones, el azul suele ser utilizado para parecer 'cool', los colores vivos se asocian a lo positivo, los obscuros 
a lo negativo. Busch afirma que no existen reglas o leyes válidas que permitan interpretar un determinado color. La manera en la que los colores son experimentados depende de cuestiones históricas y culturales. Por último, lo que representan cada uno de los elementos visualizados en los retratos, y las relaciones que se tejen entre ellos, puede no ser inmediatamente discernido del retrato mismo, por lo que es necesaria la interpretación y la explicación misma del autor del retrato lingüístico.

En definitiva, los retratos lingüísticos pueden ser entendidos como espacios que se estructuran y configuran lingüística y discursivamente a través de metáforas de la imagen y de las lenguas produciendo diferentes tipos de simbolización (Busch, 2018: 11). El uso de la silueta presupone una referenciación del cuerpo que evoca la dimensión corporal y emocional del lenguaje. Así, las diferentes representaciones, actitudes y posturas con respecto a las lenguas, variedades de lengua o hacia las prácticas de lenguaje mismas pueden ser expresadas e interpretadas a través de diversos marcos de análisis metafóricos estructurados. A su vez, estas representaciones, actitudes y posturas son objeto de evaluaciones lingüísticas e ideológicas.

En sociolingüística, varios trabajos de este tipo han sido desarrollados basándose en enfoques etnográficos centrados en los hablantes y que, además, utilizan dibujos como instrumento de elicitación (Busch, 2006; Purkarthofer, 2018). Busch (2018: 1) afirma, por ejemplo, que la silueta ha sido utilizada por más de veinticinco años en procesos de reflexión lingüística y para promover sensibilidad sobre el manejo del multilingüismo por parte de los hablantes. En los últimos años, se ha establecido como un instrumento de investigación fundamentado en los trabajos del Research Group Spracherleben (Experiencia vivida del lenguaje o the lived experience of language $)^{6}$ de la universidad de Viena, del cual Busch hace parte.

En este trabajo, el objetivo es describir las representaciones de la diversidad sociolingüística que tienen los jóvenes estudiantes escolarizados en escuelas de Leticia y de su periferia a partir de la recolección de retratos lingüísticos y del análisis interpretativo de la representación corporal y metafórica de sus repertorios plurilingües. De esta manera se intenta comprender el mundo experimentado/vivido (lifeworld) de los actores sociales (Busch, 2017, 2018) a través de la representación que ellos hacen de sus repertorios lingüísticos.

6 http://heteroglossia.net/Home.2.0.html 


\section{Contexto sociolingüístico y recolección de datos empíricos}

Los datos que analizo en este trabajo provienen de una serie de talleres sobre descripción de repertorios lingüísticos llevados a cabo en escuelas de Leticia y su periferia. Para este trabajo de sociolingüística, se considera la escuela como espacio de entrada privilegiado ya que es uno de los lugares donde no solo se refleja la diversidad sociocultural de la región, sino que también es un espacio institucional en el cual lo lingüístico está determinado por las relaciones de poder discursivamente manifestadas (Purkarthofer, 2018). Además, la escuela juega potencialmente un papel importante en la construcción social y discursiva de las desigualdades, y en su naturalización y legitimación (Martín Rojo, 2015). Asimismo, se trata de un espacio permanentemente constreñido por las ideologías homogeneizadoras que predominan a pesar de los esfuerzos que hacen muchas comunidades, organizaciones, actores sociales y educadores por reconocer y reivindicar la pluralidad.

En Leticia y su periferia, hay 9 instituciones educativas de secundaria y más de 30 escuelas de nivel primaria y preescolar que acogen a estudiantes mestizos e indígenas de la región. En teoría, en estas escuelas se aplican programas de etnoeducación ${ }^{7}$; sin embargo, poner en práctica estos programas no siempre resulta fácil para los etnoeducadores, por lo que los estudiantes terminan, en muchos casos, siguiendo una instrucción más occidentalizada.

Dentro del marco de la etnoeducación, en algunas instituciones, las materias como las ciencias sociales son reinterpretadas. Así, en estas clases se abordan contenidos culturales haciendo énfasis en las prácticas tradicionales y ancestrales de las comunidades indígenas.

\footnotetext{
7 Según Calvo Población y García Bravo (2013: 345), la etnoeducación en Colombia surge a mediados de los ochenta como un proyecto gubernamental que tiene por objetivo "normalizar y regularizar la mayoría de las experiencias educativas iniciadas por las organizaciones indígenas en la década anterior" bajo la bandera ideológica del "etnodesarrollo" y de la "interculturalidad". Algunas iniciativas de educación para las comunidades indígenas que se desligaron de esto fueron, según estos autores, la Educación Comunitaria, Educación Bilingüe Intercultural y Educación Multicultural. Asimismo, aseguran Calvo y García, la etnoeducación se convirtió en la política oficial del Estado colombiano desde 1985 y actualmente es el Ministerio de Educación la entidad que se encarga de dictar las bases para su implementación. Sin embargo, a pesar de que la etnoeducación "fue nutrida en su génesis por premisas ideológicas y políticas cargadas de un indigenismo participativo que pretendía elaborar no una política para indios, sino con los indios involucrando a la población indígena [...] sus perspectivas de éxito en el plano de lo real han sido enfáticamente desalentadoras." (Cardona \& Echeverri Restrepo, 1997: 83-84).
} 
Aunque no todos los etnoeducadores hablan las lenguas de los estudiantes, estos se esfuerzan por poner de relieve y transmitir los saberes tradicionales de los pueblos indígenas presentes en la zona. Los contenidos de estas clases se organizan en torno a actividades como tallar, tejer, buscar los tintes naturales y designarlos en lenguas indígenas, describir lo que provee la naturaleza, sensibilizar a los estudiantes al turismo sostenible, al respeto por el territorio sagrado, al cuidado del resguardo, a la horticultura y al cuidado del medio ambiente.

Sin embargo, según algunos etnoeducadores, la dificultad para aplicar los programas de etnoeducación en las escuelas en términos de medios, recursos y de formación de docentes hace que muchos profesores desistan de la enseñanza tradicional indígena y se enfoquen más en una educación occidental como lo afirma una educadora: "Pero no todos los profesores hablan el mismo idioma [...] todos los profesores no son, no entienden que somos un, un, una institución indígena, entonces, como no todos saben, entonces solamente se enfocan en lo occidental, en lo occidental y dejan aparte lo que es lo tradicional".

Este tipo de discurso es consecuencia del peso de las ideologías lingüísticas y de las políticas lingüísticas hegemónicas que terminan por imponerse en la escuela. Una muestra de esto es el hecho de que, en las clases de cultura, por ejemplo, la transmisión de contenidos se da a menudo en español y el uso de las lenguas indígenas por parte de los profesores y de los estudiantes es mínimo o incluso inexistente. Además, la disposición física misma de las aulas de clases en muchas instituciones obedece a una lógica de clase al estilo occidental en la que el maestro ocupa un lugar preponderante al frente y los estudiantes están distribuidos de manera homogénea en la parte de atrás. Esta configuración del espacio no parece favorecer la práctica de actividades culturales propias de los grupos étnicos.

Para Cardona y Echeverri Restrepo (1997: 81-83), la etnoeducación y el etnodesarrollo, además de haber sido concebidos como políticas estatales para transformar y condicionar la alteridad en América Latina, fueron adoptados por diversas instituciones interesadas en llevar a cabo programas de diversa índole en la región obligando a los discursos de los pueblos nativos a una reinterpretación y depuración de sus propios intereses. En este sentido, la etnoeducación se ha consolidado como "una variante de los discursos hegemónicos" (1997: 83) que se enmarca de manera más amplia en procesos de 
homogeneización asociados a modelos económicos capitalistas en la era de la globalización, como lo sugieren estos autores:

\begin{abstract}
El modelo de globalización amparado en los preceptos de la modernidad se ha extendido a lo largo y ancho de la inmensa selva [la Amazonia]; una política de homogeneización que dictamina, por encima de lo propio, un nuevo orden cultural y social, afincado en los cánones del sistema económico capitalista y en las estructuras ideológicas de la "sociedad occidental" (1997: 81).
\end{abstract}

A pesar de esto, la escuela representa un lugar importante de acceso a informaciones que pueden resultar interesantes para comprender la diversidad sociocultural de la Amazonia. En este sentido, decidí visitar dos escuelas de Leticia y dos de su periferia para proponer un taller sobre la descripción de repertorios lingüísticos dirigido a los estudiantes de secundaria. Intervine en la mayoría de los grados (sexto a once) en la clase de Ciencias Sociales en las que se imparten contenidos culturales. Les propuse a profesores y estudiantes un taller lúdico que permitió representar sus repertorios lingüísticos desde la perspectiva empírica, biográfica y multimodal que orienta este trabajo. Cada taller duró entre una y dos horas. La idea era que los estudiantes representaran las lenguas a las que han estado expuestos durante su vida, ya sea por el aprendizaje en la escuela, en la familia, en la comunidad, en la televisión, en internet, etc. Pero también se trataba de obtener datos relevantes para el análisis de la trasmisión de las lenguas indígenas de una generación a otra, para el análisis de las representaciones de la diversidad y actitudes lingüísticas, para el estudio de las ideologías lingüísticas en un contexto de diversidad social y cultural como el de Leticia. Para este artículo, solamente me centraré en la representación de la diversidad que tienen los estudiantes del contexto en el que están inmersos.

Los estudiantes tenían que describir sus repertorios lingüísticos a través de la silueta propuesta por Busch (ver figura 1) en la que se representara visualmente y con colores las lenguas y variedades de lengua de sus propios repertorios teniendo en cuenta la siguiente definición de repertorio lingüístico que fue utilizada en el taller:

Un repertorio lingüístico puede estar compuesto de elementos de diferentes lenguas o variedades de lengua que hemos aprendido a lo largo de nuestras vidas, en casa y fuera de ella. También pueden hacer parte de nuestros repertorios las lenguas a las que estamos expuestos cotidianamente y que deseamos aprender como las que les es- 
cuchamos a los abuelos, a los padres, a los compañeros de clase en la escuela, a los miembros de otras comunidades; o aquellas que aparecen en reuniones, medios de comunicación, medios virtuales, y que poco a poco, activa o pasivamente, nos las vamos apropiando.

Luego, se les pedía que presentaran oralmente por qué han utilizado un determinado color y por qué lo han asociado a una determinada lengua o variedad de lengua y a una determinada parte del cuerpo. En total obtuve 72 siluetas acompañadas de sus respectivas presentaciones orales y, en algunos casos, de conversaciones más informales en las que los estudiantes profundizaban sus explicaciones.

\section{Representaciones de la diversidad sociolingüística como ex- periencia vivida}

Para este artículo, mostraré solamente cuatro retratos lingüísticos para ilustrar cómo se representan los estudiantes de estas escuelas la diversidad que los rodea en términos de experiencia vivida. Veremos cómo los estudiantes experimentan la diversidad en términos de lo transnacional y de lo local a pesar del papel hegemónico de las ideologías lingüísticas dominantes reflejadas sobre todo en la práctica del español. Veremos también que la diversidad se manifiesta a través del interés por la lengua o la variedad de la lengua del otro.

\subsection{Experimentación de lo transnacional y de lo local}

Andrea es una estudiante mestiza de una escuela secundaria de la zona urbana de Leticia. Es originaria de esta ciudad, pero tiene contacto permanente con sus abuelos que viven en Brasil. Vivió dos años en Bogotá ya que su madre obtuvo en algún momento un empleo en la capital. En su silueta (figura 2), Andrea declara hablar español, portugués, inglés, pero también dos variedades del español que ella distingue bien: el rolo y el peruano.

En su representación oral, Andrea explica que ha marcado el español mayoritariamente en su silueta porque es lo que ella habla en su cotidianidad: "El español lo marqué con, [...], lo marqué harto porque es lo que hablamos nosotros". Además, lo ha relacionado con una parte importante de la silueta: la cabeza. Esto puede ilustrar la importancia del español en la comunicación de la vida cotidiana. Además, se observa una estructuración vertical, incluso de jerarquización de las lenguas, en la que el español ocupa la parte superior de la silueta y al que se le asigna metafóricamente un espacio más grande en compa- 
ración con las demás lenguas. El hecho de haber pintado el español en la totalidad de la cabeza confirma la representación de los espacios grandes-pequeños y del arriba-abajo como metáforas de lo importante y menos importante. Aquí parecen confirmarse las tendencias observadas en los trabajos de Busch en lo que respecta a los marcos metafóricos de interpretación usualmente observados en las siluetas que fueron menciona-

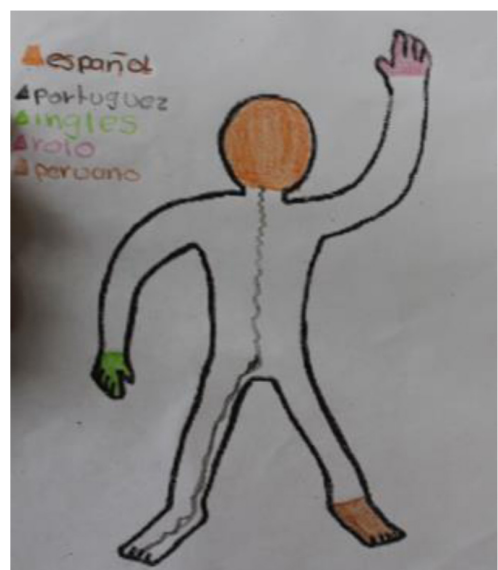

Figura 2. Retrato lingüístico de Andrea dos en la segunda sección de este artículo.

Por otro lado, Andrea se expresa en la primera persona del plural "nosotros" incluyéndose a sí misma en una comunidad de práctica más amplia: la de los hispanohablantes mestizos de Leticia. Esto podría interpretarse como una reivindicación de su afiliación a la población mayoritaria. Asimismo, Andrea hace alusión a la presencia del portugués en su repertorio lingüístico. Explica que como sus abuelos viven en Brasil, probablemente en Tabatinga, ella los visita casi todos los días: "El portugués lo marqué hasta abajo porque mis abuelos, eh, viven en Brasil y pues, prácticamente yo voy casi todos los días". Esta movilidad transnacional cotidiana la ha expuesto al portugués, lengua que manifiesta hablar: "más o menos, no mucho, pero sí lo hablo y lo entiendo correctamente", dice. Llama la atención en su silueta la línea negra del portugués que baja (o sube) conectando la cabeza con los pies. Probablemente, Andrea quiso representar así la asociación entre esta lengua y la facilidad con la que se moviliza cotidianamente entre Colombia y Brasil, lo que ilustra en resumidas cuentas la facilidad de movilidad transfronteriza que experimentan, como ella, muchos hablantes de Leticia. Así, la movilidad espacial de Andrea está asociada a los pies, que en este caso no se interpretan bajo la dicotomía arriba/abajo como metáfora de lo importante y menos importante, sino como instrumentos de desplazamiento y de recorrido espacial que permite una movilidad transnacional relativamente fácil como la que se observa en el trapecio amazónico.

De manera interesante, Andrea manifiesta además hablar dos variedades específicas del español: el "rolo", que es la forma como se le denomina al español de Bogotá, y el "peruano": 
Y el, el rolo pues porque yo estuve dos años en Bogotá y pues yo me lo sé de memoria. Y el peruano pues porque viví con unos peruanos a lado de mi casa y pues siempre yo, como que soy metidita y pues quise aprender también el peruano y pues me lo sé también de memoria.

Ambas variedades hacen también parte de la experiencia vivida de Andrea. El "rolo", lo aprendió de 'memoria' durante los años que estuvo con su madre en Bogotá y estuvo expuesta al "peruano" ya que sus vecinos en Leticia eran del Perú. Es interesante observar que ambas variedades se oponen verticalmente arriba y abajo respectivamente. Esto podría interpretarse como una metáfora de lo importante / menos importante. Sin embargo, cabe resaltar la actitud positiva de Andrea con respecto a la variedad de español del Perú, que a menudo es objeto de comentarios jocosos o incluso de mofa por parte de los chicos en la escuela. Andrea muestra en efecto su curiosidad e interés por hablar como sus vecinos probablemente por razones de amistad, de proximidad y/o de afiliación.

El retrato lingüístico de Andrea, como el de muchos estudiantes de la zona urbana de Leticia, incluye variedades del español y el portugués. Mientras que, de manera minoritaria, en los retratos de los estudiantes indígenas se incluyen las lenguas étnicas. Tal es el caso del retrato de Julia, estudiante tikuna escolarizada, al igual que Andrea, en la zona urbana de Leticia. Julia nació en Puerto Nariño, una localidad situada sobre el río Amazonas a unos 60 kilómetros de Leticia y unos 20 de Caballococha en el Perú. Sus abuelos paternos son tikunas del Perú. Su padre nació en la costa caribe colombiana y habla español de la región de la Costa. Su madre también tiene orígenes tikunas, pero la abuela de Julia era italiana.

Julia afirma que su madre le ha intentado enseñar el italiano ya que probablemente su abuela se lo había transmitido: "mi mamá me ha enseñado un poco de italia, pero yo casi no, no, no sé pronunciar bien italia...italiano". Por su parte, los abuelos paternos que son tikunas del Perú le han enseñado a hablar tikuna desde pequeña por lo que probablemente es su lengua de primera socialización: "mis abuelos, parte de papá, son tikunas, ellos hablan tikuna muchos, ellos me ha enseñado desde niñita he hablado tikuna".

Es interesante observar como el tikuna está representado en color morado en la parte central de la silueta como si Julia quisiera darle un valor central en su vida. Si bien no se le puede dar una interpretación objetiva al color utilizado por Julia, el lugar que ocupa el tiku- 


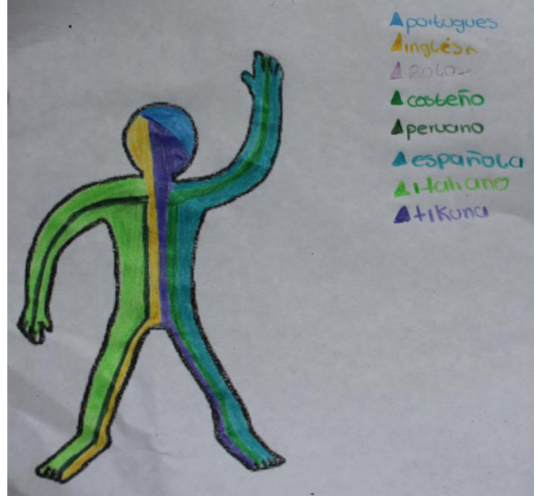

Figura 3. Retrato lingüístico de Julia

na en la silueta puede asociarse, como lo muestran los trabajos de Busch, a los sentimientos y emociones. En el caso de Julia, el tikuna está asociado a las relaciones familiares (sentimentales y emocionales) que la unen a sus abuelos paternos. Asimismo, el espacio en que la lengua tikuna está representada es menor si se lo compara con el español. Esta metáfora del espacio y de la cantidad remite al uso minoritario del tikuna por parte de Julia. A este respecto, ella explica que está olvidando la lengua tikuna: "sí, he aprendido mucho tikuna y he aprendido todo eso, pero, como yo también ya me estoy olvidando todo eso, 'tonces, me tengo que memorizar todo eso". Esto se debe probablemente al peso hegemónico del español, que aparece representado consecuentemente en la silueta y en la explicación de Julia: "hablo mucho español, eh como yo no nací aquí, [...] pues, ya estoy aprendiendo a hablar español también". El uso declarado del español y del tikuna, tanto en la silueta como en la explicación de Julia, está claramente determinado por el prestigio asimétrico de estas dos lenguas. El español, por un lado, es la lengua de mayor prestigio que hay que aprender obligatoriamente cuando se viene de otro lugar: "como yo no nací aquí" y "ya estoy aprendiendo a hablar español también". Mientras que el tikuna es la lengua de menos prestigio que tiende a olvidarse si no se hace un esfuerzo: "como yo también ya me estoy olvidando todo eso, 'tonces, me tengo que memorizar todo eso".

Julia, al igual que Andrea, reconoce la variedad de español peruano como parte de su repertorio lingüístico. Como sus abuelos paternos son tikunas del Perú, ella ha estado también expuesta, no solo al tikuna sino también al español peruano. Asimismo, el portugués, como en la gran mayoría de los retratos dibujados en las escuelas urbanas, aparece casi obligatoriamente. Julia dice: "hablo portugués, pero casi no lo entiendo un poquitico hay veces, pero sí, portugués lo hablo mucho, mucho cuando nos toca y toca aprender todo". Estas declaraciones, así como el hecho de haber representado el portugués en la cabeza, una parte importante del cuerpo, reflejan la importancia que tiene esta lengua para los intercambios transfronterizos cotidianos en la zona. 
De la misma manera, en las escuelas situadas en la periferia de Leticia, donde por lo general hay más estudiantes indígenas escolarizados con respecto a las escuelas situadas en zona urbana, se observan estas mismas tendencias en los retratos lingüísticos: presencia de variedades del español, portugués, lenguas indígenas, lenguas internacionales de la educación como el inglés. Sin embargo, en gran parte de los retratos lingüísticos, como lo ilustran los de Juan y Pedro (figuras 4 y 5), estudiantes tikunas de escuelas secundarias de la periferia de Leticia, aparecen denominaciones específicas para la variedad del español local: español de Leticia (Juan) y español amazónico (Pedro).

Esto resulta interesante ya que estas denominaciones particulares expresan la forma de hablar local y a su vez la distinguen de las demás. Esto se observa en las declaraciones de Pedro, por ejemplo: "El color verde, eh, representa español amazónico porque nosotros no podemos comparar español con el de Bogotá porque el de Bogotá es muy diferente, a lo mismo de lo de Boyacá es muy diferente".

Por su parte, Juan afirma que el español que conoce es solo el español de Leticia ya que no ha recorrido aún otros lugares donde se hable diferente:

el español es el que más resalta, es el color verde, oscuro, porque no he recorrido mucho, como dice el profesor, otra, otras partes, otras ciudades sino solamente l'español de aquí de Leticia, o sea es como más, eh, un español local por decirlo así.

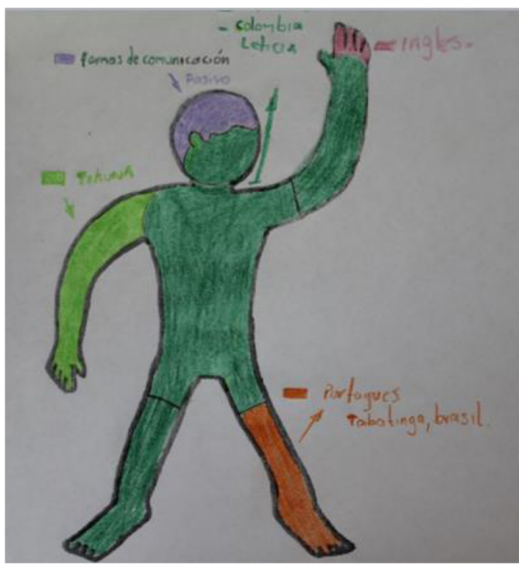

Figura 4. Retrato lingüístico de Juan

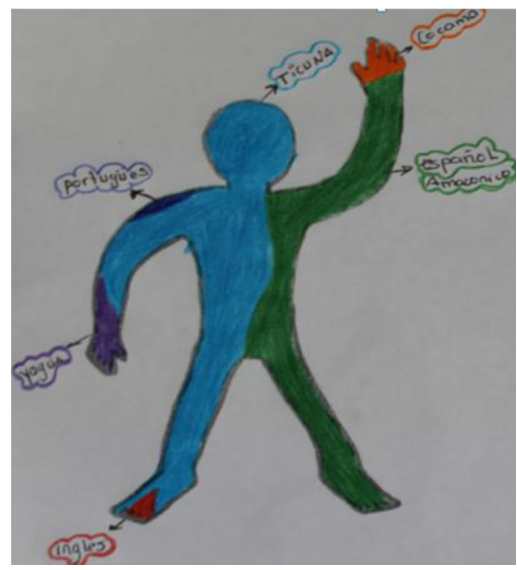

Figura 5. Retrato lingüístico de Pedro 
Estas denominaciones específicas para el español de Leticia dicen mucho sobre la reivindicación de lo local y, por consiguiente, de la diferenciación como manifestación de una identidad particular a la cual los jóvenes parecen afiliarse. A su vez, la representación del español local con el color verde, tendencia que se observa en muchos de los retratos lingüísticos, está asociado a lo amazónico y probablemente a la biodiversidad de la región.

\subsection{Experiencia vivida e interés por la lengua del otro}

En el retrato lingüístico representado en la figura 5, Pedro representó el tikuna y el español amazónico como las lenguas que más habla en la mayor parte del dibujo. Para él, el tikuna es la lengua en la que puede hablar, cantar y jugar, es decir, realizar actividades que hacen parte de lo extraescolar y que están probablemente asociadas más a ámbitos no institucionales o incluso más íntimos, en la comunidad: "El color, el color azul representa a lo tikuna que [es] lo que más hablo y lo que entiendo y hablo, juego, puedo cantarlo también". En efecto, Pedro estudia en una escuela de la periferia de Leticia y se desplaza diariamente desde su casa, situada en una zona donde viven familias tikunas, hasta la escuela. El hecho de vivir en su comunidad hace que la práctica del tikuna sea importante para Pedro y se manifieste en diversos ámbitos de uso. Así, el azul, color asociado a aspectos positivos en los trabajos de Busch, ocupa un lugar importante en la silueta de Pedro en términos de espacio, al mismo tiempo que se refiere positivamente a los usos que él hace de la lengua (jugar, cantar, etc.).

Además, por su experiencia vivida, Pedro manifiesta estar aprendiendo el cocama, lengua en la que ha aprendido a escribir, hablar y a saludar, así como el yagua que también decidió aprender a hablar y a escribir. Ambos están representados en las manos:

eh, cocama, decidí pintar en las punta de mis manos porque he aprendido a escribir, a hablar y saludar en ella; yagua en la mano, en la mano, derecha, abajo, porque también decidí, decidí aprender a escribir y también lo hablo un poco.

Al igual que en los trabajos de Busch (2018), vemos cómo se asocian a las manos metáforas de socialización con los demás: "he aprendido [...] a saludar en ella [cocama]", y de instrumentalización como la realización de actividades como el escribir. Este interés por aprender la lengua del otro radica en el hecho de que Pedro ha participado en varios talleres de lenguas indígenas propuestos por agentes externos a las comunidades, que pueden ser etnoeducadores, investi- 
gadores u otros actores sociales. Lo que resulta interesante es que normalmente estos talleres de formación en lenguas indígenas están orientados a su recuperación por parte de los indígenas de las etnias mismas. Sin embargo, en el caso de Pedro, siendo tikuna, este interés, que no es aislado, adquiere una importancia particular ya que evoca no solo los contactos a los que él está expuesto en su entorno, sino las posibilidades de intercambio que le sugiere el hecho de poder hablar y escribir en otras lenguas indígenas.

De la misma manera, la actitud hacia la lengua (o variedad de lengua) del otro también se ve explícita en el retrato lingüístico de Andrea (figura 2), y en cierta medida en el de Julia (figura 3). cuando manifiestan interesarse por hablar como sus vecinos o familiares peruanos. Estas actitudes pueden interpretarse como la voluntad de expresar significados o posturas sociales de afinidad hacia el otro y de afiliación a otros grupos sociales. Estas posturas no resultan para nada aisladas y son más bien recurrentes en el contexto estudiado. Por ejemplo, un estudiante de una escuela de Leticia asegura que, como la lengua tikuna es mayoritaria en la región, por lo general, los que no son hablantes de esta lengua suelen utilizar formas lingüísticas del tikuna con funciones sociales variadas. Estas funciones pueden ser de afiliación al grupo, de burla, de negociación de posturas epistémicas y afectivas, de sentimiento de legitimidad, etc. En este sentido, el interés por la lengua del otro, sin que esto signifique llegar a ser "competente" en dichas lenguas, muestra que las prácticas de lenguaje de los estudiantes pueden ser extremadamente dinámicas, más allá de las declaraciones hechas en los retratos lingüísticos.

\section{Discusión y conclusiones}

La descripción de las representaciones de los repertorios lingüísticos de los estudiantes desde una perspectiva empírica, etnográfica como experiencia vivida destaca varios aspectos que vale la pena poner de relieve. El primero de ellos es la posibilidad de interpretar metafóricamente las representaciones, actitudes y posturas asumidas frente a sus propios repertorios lingüísticos. Hemos visto que los hablantes pueden asignar a sus repertorios lingüísticos jerarquías con respecto al uso de la lengua (importante vs menos importante, más espacio vs menos espacio, arriba vs abajo), expresar la socialización, la movilidad y el interés por la lengua del otro (metáfora de lo exterior), así como expresar emociones y sentimientos (metáfora de lo interior).

El segundo aspecto es el de la agentividad de los hablantes frente al papel hegemónico de la escuela con respecto a la enseñanza del 
español, pero también del inglés, ambas lenguas internacionales y de prestigio. Por ejemplo, para algunos estudiantes, aprender inglés puede ser algo positivo como en el caso de Julia: "el inglés me gusta mucho, es el área que me gusta, y he aprendido a hablar inglés, y le he analizado lo entiendo pero casi no lo pronuncio bien". Mientras que otros estudiantes pueden desarrollar actitudes hostiles hacia el aprendizaje de esta lengua como en el caso de Juan (figura 4), quien afirma haber pintado el inglés solamente en los dedos ya que para él: "el inglés [...] es como cogerlo y hacerlo añicos". El español, sin embargo, a pesar de ser lengua mayoritaria en la que se imparten y trasmiten los contenidos de los programas, puede llegar a beneficiarse de apelativos que subrayan lo local como el caso del "español amazónico", "español de Leticia" o "español leticiano" mencionados por muchos de los estudiantes. Esta expresión de lo local le atribuye a la variedad de español hablada en Leticia y su periferia una identidad propia reivindicada y asumida por los propios hablantes. Y esto puede ser una forma de resistir a la homogeneización o de existir en ella.

El tercer aspecto que vale poner de relieve es el de cómo la heterogeneidad y lo transfronterizo se reflejan en los repertorios lingüísticos de los estudiantes. En efecto, muchos de estos grupos mantienen relaciones transnacionales permanentes con sus lugares y comunidades de origen a través de incesantes vaivenes, del intercambio de flujos importantes de información, de intercambios económicos, materiales, inmateriales, tal y como se ha descrito en otros contextos de movilidad transnacional (Sánchez, 2007). Así, como lo sugieren Cardona y Echeverri, la idea de la Amazonia como un paraíso selvático inalterable y estático no es viable ya que eso equivaldría a negar el contacto histórico de poblaciones (1997: 82). De la misma manera, el transnacionalismo, o como lo dice Chaumeil (2000: 54), las situaciones transfronterizas, tienen necesariamente implicaciones en la constitución y la dinámica de las identidades culturales, étnicas, religiosas, territoriales y regionales de la población indígena, mestiza y andina de la región.

Todo esto se ve reflejado de alguna manera en los retratos lingüísticos de los estudiantes. Sin embargo, lo analizado aquí no deja de ser solo una representación posible de lo heterogéneo y de lo transnacional, entre muchas otras. Además, el estudio empírico de sus repertorios lingüísticos como experiencia vivida y a través de la silueta, no necesariamente es el reflejo de lo que realmente son sus repertorios lingüísticos ni del uso que los hablantes hacen de ellos. Tampoco es una reconstrucción objetiva de ningún proceso de adquisición como lo sugiere Busch (2012). Se trata de un método de recolección de 
datos empíricos que ilustran lo heterogéneo que pueden ser los recursos lingüísticos y que se han constituido gracias a la experiencia vivida, en un contexto de superdiversidad. Es un punto de referencia que puede permitir obtener informaciones sobre las prácticas de lenguaje de los actores sociales, de sus recursos, actitudes, representaciones y posturas. Estas informaciones se deben completar, por supuesto, con la observación etnográfica de prácticas de lenguaje socialmente situadas, tanto en clase como fuera de ella. Esta tarea constituye una agenda de investigación a venir en la que se pueden inscribir fenómenos lingüísticos y sociales extremadamente complejos e interesantes como los que se observan en situaciones de superdiversidad. Por ejemplo, el hecho de que los no hablantes de tikuna puedan apropiarse de formas particulares de esta lengua para re-utilizarlas, asignándoles nuevos significados sociales o el hecho de que los repertorios plurilingües se modifiquen y se enriquezcan gracias a la movilidad transnacional.

Finalmente, el hecho de proponer la actividad de representación de los repertorios lingüísticos como un taller lúdico en el marco de la clase de cultura (Ciencias Sociales) constituye también una oportunidad para los estudiantes, profesores y actores sociales de expresar la diversidad en la que están inmersos. Una diversidad que está eclipsada por los discursos hegemónicos arriba mencionados, pero puesta en valor en los retratos lingüísticos de los estudiantes de escuelas de Leticia y su periferia.

\section{Bibliografía}

Blommaert, J., \& Rampton, B. (2011). Language and Superdiversity. Diversities, 13(2), 1-21.

Busch, B. (2006). Language Biographies -approaches to multilingualism in education and linguistic research. En B. Busch, A. Jardine, \& A. Tjoutuku (Eds.), Language biographies for multilingual learning Vol. 24 (pp. 5-17). Cape Town: PREAESA occasional Papers.

Busch, B. (2012). The Linguistic Repertoire Revisited. Applied Linguistics, 33(5), 503-523.

Busch, B. (2017). Expanding the Notion of the Linguistic Repertoire: On the Concept of Spracherleben-The Lived Experience of Language. Applied Linguistics, 38(3), 340-358. https://doi. org/10.1093/applin/amv030 
Busch, B. (2018). The language portrait in multilingualism research: Theoretical and methodological considerations. Working $\mathrm{Pa}$ pers in Urban Language \& Literacies, (236), 1-13.

Butler, J. (1997). Excitable speech: a politics of the performative. New York: Routledge.

Calvo Población, G. F., \& García Bravo, W. (2013). Revisión crítica de la etnoeducación en Colombia. Historia de La Educación: Revista Interuniversitaria, (32), 343-360.

Cardona, M., \& Echeverri Restrepo, J. A. (1997). Etnoeducación y cultura: elementos para una caracterización de la educación indígena en el departamento del Amazonas. Boletín de Antropología Universidad de Antioquia, 11(28), 71-92.

Chaumeil, J.-P. (2000). Par-delà trois frontières, l'espace central du trapèze amazonien (Pérou, Colombie, Brésil). Autrepart, (14), 53-70.

De Campos Barbosa, G. (2008). Atitudes em Fronteira: O Caso de Tabatinga e Letícia. Forma y Función, (21), 303-324.

Derrida, J. (1998). The monolingualism of the other: the prosthesis of origin. Stanford, California: Stanford University Press.

Du Bois, J. W. (2007). The stance triangle. En R. Englebretson (Ed.), Stancetaking in Discours, subjectivity, evaluation, interaction (pp. 139-182). Amsterdam / Philadelphia: John Benjamins Publishing Company.

Echeverri Restrepo, J. A. (2011). Presentación. En J. A. Echeverri Restrepo \& C. Pérez Niño (Eds.), Amazonia colombiana: imaginarios y realidades (Memorias de la Cátedra Jorge Eliecer Gaitán, pp. 15-18). Bogotá: Editorial Universidad Nacional de Colombia.

Fagua Rincón, D. (2004). Diagnóstico sociolingüístico del departamento del Amazonas, los Lagos (periferia de Leticia): contacto y cambio. Universidad Nacional de Colombia, Bogotá. Recuperado de http://www.bdigital.unal.edu.co/1301/

Fernández Mallat, V. (2018) Cuando la población migrante desmiente los discursos dominantes: autorretratos lingüístico-cultura- 
les de jóvenes hablantes bilingües del español en Suiza. Visitas al patio, (12), 119-143. Doi https://doi.org/10.32997/20270585-vol.0-num.12-2018-2109

Gasché, J., \& Vela Mendoza, N. (2011). Sociedad bosquesina (Vol. I). Iquitos, Perú: Instituto de Investigaciones de la Amazonia Peruana (IIAP).

Gumperz, J. J. (1964). Linguistic and social interaction in two communities. American Anthropologist, 66(6), 137-153.

Jager, A. de, Tewson, A., Ludlow, B. y Boydell, K. (2016). Embodied Ways of Storying the Self: A Systematic Review of Body-Mapping. Forum Qualitative Sozialforschung / Forum: Qualitative Social Research, 17(2), Art. 22.

Kroskrity, P. V. (2006). Language Ideologies. En A. Duranti (Ed.), A Companion to Linguistic Anthropology (pp. 496-517). Oxford, UK: Blackwell Publishing Ltd.

Mahecha Rubio, D. (2011). Escuela y multiligüismo en Amazonia: un desafío contemporáneo. En J. A. Echeverri Restrepo \& C. Pérez Niño (Eds.), Amazonia colombiana: imaginarios y realidades (Memorias de la Cátedra Jorge Eliecer Gaitán, pp. 293-309). Bogotá: Universidad Nacional de Colombia.

Martín Rojo, L. (2015). The Social Construction of Inequality in and through Interaction in Multilingual Classrooms. En N. Markee (Ed.), The Handbook of Classroom Discourse and Interaction (pp. 490-505). Estados Unidos: John Wiley \& Sons, Ltd.

Meyerhoff, M. (2008). Communities of Practice. En J. K. Chambers, P. Trudgill, \& N. Schilling-Estes (Eds.), The Handbook of Language Variation and Change (pp. 526-548). Oxford, UK: Blackwell Publishing Ltd.

Molina, S. L. R. (2008). Aproximación al estudio de las actitudes lingüísticas en un contexto de contacto de español y portugués en el área urbana trifronteriza Brasil-Colombia-Perú. Forma y Función, (21), 251-285.

Patrick, P. L. (2008). The Speech Community. En J.-K. Chamber, P. Trudgill, \& N. Schilling-Estes (Eds.). Handbook of language variation and change (pp. 573-597). Oxford: Backwell Publishing Ldt. 
Purkarthofer, J. (2018). Children's drawings as part of School Language Profiles: Heteroglossic realities in families and schools. Applied Linguistics Review, 9(2-3), 201-223. https://doi. org/10.1515/applirev-2016-1063.

Sánchez, P. (2007). Urban immigrant students: how transnationalism shapes their world earning. The Urban Review, 39(5), 489-517.

Sánchez Moreano, S. (2018). Negociación de posicionamientos sociales (stances) a través del debilitamiento del fonema /s/ en el español hablado por los quichuas ecuatorianos en Cali (Colombia). Pragmática Sociocultural, 6(1), 33-70.

Vertovec, S. (2007). Super-diversity and its implications. Ethnic and Racial Studies, 30(6), 1024-1054. 